\title{
Promiscuous application of toxic agrochemicals on pineapple: health hazard implications in Bangladesh
}

\author{
${ }^{1 *}$ Proshad, R., ${ }^{1}$ Islam, M.S., ${ }^{2}$ Islam, M.N., ${ }^{3}$ Hossain, M.R., ${ }^{4}$ Kormoker, T., ${ }^{5}$ Islam, M.S. and \\ ${ }^{6}$ Billah, K.M.M.
}

${ }^{1}$ Department of Soil Science, Patuakhali Science and Technology University, Dumki, Patuakhali-8602, Bangladesh ${ }^{2}$ Department of Horticulture, Patuakhali Science and Technology University, Dumki, Patuakhali-8602, Bangladesh ${ }^{3}$ Department of Entomology, Patuakhali Science and Technology University, Dumki, Patuakhali-8602, Bangladesh ${ }^{4}$ Department of Emergency Management, Patuakhali Science and Technology University, Dumki, Patuakhali-8602, Bangladesh

${ }^{5}$ Forestry and wood technology discipline, Life science school, Khulna University, Khulna-9208

${ }^{6}$ Department of Plant Pathology, Patuakhali Science and Technology University, Dumki, Patuakhali-8602, Bangladesh

Article history:

Received: 16 July 2017

Received in revised form: 25

September 2017

Accepted: 27 September 2017

Available Online: 2 October 2017

\section{Keywords:}

Pineapple,

Health Hazard,

Bangladesh,

Cancer risk,

Ethephon,

Calcium carbide

\section{DOI:}

https://doi.org/10.26656/fr.2017.2(2).113

\begin{abstract}
This review paper explained the human health hazard implication of toxic agrochemicals applied in pineapples for quick growth and ripening it. Different hormones and toxic chemicals are being used continuously by farmers on standing unripe pineapples in Bangladesh. After harvesting, some toxic chemicals are sprayed to long-term storage. Toxic agrochemicals like ethephon (2-chloroethylphosphonic acid), formaldehyde, superfix, harvest, promote, calcium carbide, ethylene, ripen are being extensively applied in pineapple field for artificial ripening and enhancing the fruit size of the pineapple. These pineapples are contaminated with these above toxic chemicals and it may have health hazard to children, adult and also especially pregnant women. Pineapples are being consumed by Bangladeshi people without knowing the severe health risk of these hazardous chemicals. A lot of human health problems like respiratory, neurological, immunological, hematological, reproductive, cardiovascular, developmental, dermal, genotoxic and gastrointestinal causes for consumption of this contaminated pineapples. The health effects of these toxic chemicals is so severe that toxicity will remain in the next generation. It has been proved that chemicals can alter epigenetic marks and that the same or similar epigenetic alterations can be found in patients with the disease of concern or in diseased tissues. Pineapples are colorful and large in size but lose its flavor and taste due to the application of toxic agrochemicals. After harvesting of pineapples, they are treated with formalin for protecting against microbial attack and it combats financial loss. The main purpose of this paper primarily focuses on the promiscuous application of some toxic chemicals and their implication on human health hazard in Bangladesh.
\end{abstract}

\section{Introduction}

Pineapple (Ananus sativus; Family: Bromeliaceae) is edible, juicy, a multiple tropical fruit, which develops from a spike or head of flowers and is surmounted by a crown of leaves. Pineapple is one of the most commercial fruit in the world (Baruwa, 2013). It was introduced in Bangladesh through Assam and Manipur of India and was first cultivated in Sylhet in the beginning of $20^{\text {th }}$ century. It is now cultivated in almost all the districts of Bangladesh although Tangail, Sylhet,
Dhaka, and Rangamati have more acreage under cultivation. About 45,685 ha of land are now under pineapple cultivation with a total production of about 2 , $34,865 \mathrm{~m}$ tons. The cultivated varieties are Red Spanish (ghorashal), Giant Kew (locally kalendar) and Honey Queen (jaldubi). Flowering starts from March to May and fruiting from June to September. Pineapples cover about $11 \%$ lands in the country and it is increasing every year (Banglapedia). Pineapple contains 14\% of sugar and bromelin; a protein digesting enzyme, good amount of 
citric acid, malic acid, vitamin A and B which is very much essential to the human body (Bartholomew et al., 2003). Madhupur of Tangail district is a major pineapple producing area in Bangladesh. Madhupur Garh region produces over one lakh tonnes of the delicious fruit in a year and it is sent to different parts of the country including the capital city of Bangladesh. About 17,000 acres of land have been brought under pineapple cultivation in Tangail in 2016. In recent years, it is observed that farmers are using toxic agrochemicals for artificial ripening of pineapples in Madhupur of Tangail district and it is a very serious issue in the field of food safety and people of Bangladesh have a severe health hazard due to consuming of toxic chemicals (Ur-Rahman et al., 2008). Pineapple growers are spraying hormones and toxic chemicals excessively and untimely on pineapples in Madhupur of Tangail district for increasing the size of the fruits. For this depraved practice, consumers are easily attacked with different diseases while Madhupur pineapple is losing its original taste, making it less popular to the consumers. Toxic chemicals are usually to be applied 15 days before and 15 days after the budding stage to enhance flowering of the plant and shedding of flower buds are prevented. By applying hormones in the excessive amount of the mature fruits to produce large size fruit for getting more benefits. Farmers are given suggestions by pesticides shop owners for applying these chemicals and hormones on the fruits for enhancing the sale of their hazardous chemicals. Applying excessive toxic chemicals on the fruit produce it watery and tasteless as buyers like a giant and yellow pineapples compared to the natural-sized ones. The growers thus can earn huge profit by selling the bigger fruits. A normal-sized pineapple sells for Bangladeshi taka (Tk 15-20), while a giant and more yellow pineapple for 20-30 Tk. It indeed increases great economic loss for the fruit sellers and therefore, to minimize the loss, fruit sellers sometimes prefer collecting pineapple before full maturity and artificially ripen pineapple before selling to the consumers. Farmers apply chemicals on the basis of local pesticides shop owners' instructions because they do not have a proper idea about the right use of chemicals. Naturally, all pineapple in an orchard cannot ripe at a time. About 10 to 12 fruits are ripe at a time, and taking a few pineapples to the market for sale every time is not profitable but spraying the hormones on the mature fruits before harvesting helps ripen all the fruits of an orchard together. Since there is a scarcity of local agricultural officials to the farmers, they take suggestions from pesticide sellers for buying chemicals. Agricultural officials should suggest the local farmers how much these toxic chemicals would be applied in pineapple orchard or it is very much harmful to human if these toxic chemical contaminated fruits are being consumed. These chemicals are harmful to human health for consuming the toxic chemically treated pineapples is responsible for several diseases. Diseases like liver and kidney problem may occur due to regular consumption of toxic chemical-treated fruits (Rahim, 2012). Scientists have found that weakness, dizziness, skin ulcer and heart related diseases may be caused due to regular consumption of artificial-ripened pineapples (Nagel, 1989; Fattah and Ali, 2010; Jayan, 2012). In addition, these chemicals contain impurities which are also hazardous to human health. The purpose of this study is to address the legislative, scientific and health related issues associated with artificial ripening of pineapples by different harmful chemicals.

\section{Toxic chemicals used in pineapple}

In order to get more profits, unripe pineapples are treated with several toxic chemicals which act as artificially ripening agent. Ripening agents affect ripening process of pineapple and these are ethylene, formalin, ethephon, ethereal, ethylene glycol, and calcium carbide (Singal et al., 2012).There are several toxic chemicals are being used continuously on pineapple field in Bangladesh. These toxic chemicals have a great effect on pineapples. By applying these chemicals on unripe pineapples, some chemical changes occur quickly and pineapples become larger in size, attractive and colorful with less flavor and taste. Unripe pineapples contain several classes of organic acids like malic acid, formic acid, citric acid, formic acid, tartaric acid, ascorbic acid, etc. unripe Pineapples are surely sour in taste due to these acids. These acids are converted into sugars after certain chemical changes during the ripening stage and pineapple taste sweet (Kendrick, 2009). Chlorophyll is produced and at that time it is also decomposed during the fruit ripening process. Pectin converts into pectinase and decomposition of pectin, in this case, unglues the fruit cells. The cells being able to slip past one another makes the fruit softer (Koning, 1994). After application of the toxic chemicals on unripe pineapples, these ripening processes occur quickly with a short time of vegetative growth and toxic chemicals may also enter the edible part of pineapples through several ways and the fruit becomes toxic.

\subsection{Ethylene}

Ethylene is the major ripening agent produced naturally within the fruits which initiates the process of 
ripening. A very small concentration (1 ppm) of ethylene in the air is sufficient to promote the fruit ripening process (Brady, 1987). Externally applied Ethylene triggers the natural ripening process of pineapple and therefore, can be marketed before the predicted time. Under normal conditions, ethylene is a colorless gas, which has a faint, pleasantly sweet smell. It is very reactive and flammable. It does not dissolve in water but mixes well with most organic (carbon-containing) solvents. Ethylene is one of the groups of substances known as the volatile organic compounds (VOCs).

\subsection{Formaldehyde}

Formaldehyde is a colorless, flammable, strong smelling chemical that is used in building materials and to produce many household products. Generally, it is used in pressed-wood products, such as plywood and fiberboard, permanent press fabrics, particle board, glues and adhesives, certain insulation materials paper and product coatings. In addition, formaldehyde is commonly used as an industrial fungicide, germicide, and disinfectant, and as a preservative in mortuaries and medical laboratories. Formaldehyde also occurs naturally in the environment. Nowadays, this toxic chemical is being used in unripe pineapples for enhancing the shelf life of pineapple.

\subsection{Ethephon}

Ethephon is a plant growth regulator. Its use in varies with plant species, chemical concentration and time of application. Ethephon regulates phases of plant growth and development by application to various growth sites (Kidd and James, 1991). The active ingredient ethephon is found in a variety of commercial herbicides. Trade names for products containing ethephon include Arvest, Bromeflor, Etheverse, Flordimex, Flordimex T-Extra, Cerone, Etherel, Chipco Florel Pro and Prep (USEPA, 1988; Anon., 1994). Ethephon is another agent which is used to artificially ripen fruits (Singal et al., 2012). Ethephon is often considered better than calcium carbide because pineapples treated with $1000 \mathrm{ppm}$ of ethephon required less time for ripening (48h) than other treated fruits as well as compared with the non-treated fruits. The fruits ripened with ethephone have more acceptable colour than naturally ripened fruits and have a longer shelf life (Ur-Rahman et al., 2008). Ethephon comes in RTU (ready-to-use), emulsifiable concentrate and aqueous solution formulations. It may also be used in combination with Terpal (with mepiquat-chloride) and Terpal C (chlormequat-chloride). Spraying it on unripe pineapples hasten their ripening time. A batch will ripen almost at the same time, perfect for competitive market demands. Ethephon converts to ethylene after metabolism. Ethylene is a growth and ripening agent naturally produced by plants. It can be added externally to produce a more desirable effect.

\subsection{Calcium carbide}

Calcium Carbide is widely used in different parts of the world. Once applied on the fruits, calcium carbide comes into the contact with the moisture and releases acetylene, which has fruit ripening characteristics similar to ethylene (Hoque, 2012). Calcium carbide is mostly used for ripening of fruit; while, its use is being discouraged worldwide, due to associated health hazards (Anwar et al., 2008). Secondly, calcium carbide $\left(\mathrm{CaC}_{2}\right)$ is the commonly used chemical for ripening of fruits, due to its low price and availability in the local market; however, use of this chemical in fruit industry is being discouraged worldwide due to dangers of explosion and carryover of toxic materials like arsenic and phosphorus to consumers, thus making the healthy fruit poisonous (Mariappan, 2004). Calcium carbide absorbs moisture and produces acetylene, which is a weak analog of ethylene, responsible for triggering ripening process (Cua and Lizada, 1990; Singh and Janes, 2001).

$$
\mathrm{CaO}+3 \mathrm{C} \rightarrow \mathrm{CaC}_{2}+\mathrm{CO}
$$

Industrial grade calcium carbide contains traces of arsenic and phosphorus hydride, which is hazardous for human health in direct contact (Ur-Rahman et al., 2008).

\section{Health hazard implication due to toxic chemicals contaminated pineapple consumption}

People of Bangladesh may consume contaminated fruits which are ripened by toxic hazardous chemicals. The consumers may be exposed to high health risks due to consumption of contaminated fruits. These toxic chemicals have cancer producing agents and neurological disorders are caused by it. The ultimate result is tingling sensation and peripheral neuropathy. The ripening toxic chemicals are harmful and their consumption can cause serious health problems, such as skin disease, heart disease, lung failure and kidney failure. Regular consumption of artificial ripened toxic fruits may cause weakness, dizziness, skin ulcer and heart-related diseases (Jayan, 2011; Hakim et al., 2012; Islam et al., 2015). Ethylene may enter the body due to contaminated pineapples consumption as farmers apply ethylene in unripe fruit. Ethylene is of low toxicity to humans and exposure to ethylene is unlikely to have any adverse health effects. However, inhalation of air 
containing extremely high levels of ethylene may lead to effects including a headache, drowsiness, dizziness, nausea, weakness, and unconsciousness. However, exposure to ethylene at normal background levels is unlikely to have any adverse effect on human health. Generally, the higher levels of exposure to the toxic chemical, more harmful effects will occur. Major effects have been observed in workers exposed to ethylene oxide at low levels for several months are irritation of the skin, eyes, and mucous membranes and brain and nerves function problem. Due to higher exposure to ethylene oxide may result from equipment breakdown or accidents, effects are alike and they are more toxic and harmful. There has surely some proof that ethylene oxide exposure enhances miscarriages rate in human body exposed to ethylene oxide (Butterworth and Chapman, 2007). Breathing ethylene oxide at high levels can interfere with their ability to reproduce in humans. The tolerance limit of ethylene oxide in ground spices is 50 ppm by the Food and Drug Administration (FDA). Any release to the environment greater than 10 pounds must be reported to the EPA. The Occupational Safety and Health Administration (OSHA) has set a limit of $1 \mathrm{ppm}$ over an 8-hour workday, 40-hour workweek with a short -term exposure limit (not to exceed 15 minutes) of 5 ppm. The National Institute of Occupational Safety and Health (NIOSH) recommends that average workplace air should contain less than 0.1 ppm ethylene oxide averaged over a 10-hour workday, 40-hour workweek (ATSDR, 1990).

According to the United States Environmental Protection Agency (USEPA), formaldehyde is a colorless, flammable, and strong-smelling toxic chemical. Most of us probably do not feel familiar with the name of this particular substance. However, formaldehyde is easy to find in our daily life. Sore throat, burning sensation in the nose and throat, and nasal congestion are the symptoms of upper airway irritation. Upper airways irritation most likely takes place if formaldehyde levels exceed 1 ppm. Cough, phlegm, and shortness of breath are symptoms of upper airway irritation. Lower airways irritation most likely takes place if formaldehyde levels exceed $5 \mathrm{ppm}$. Individuals with pre-existing asthma have a higher sensitivity when exposed to formaldehyde. In the case of formaldehyde levels exceed $50 \mathrm{ppm}$, it can result in pneumonia, chronic bronchitis or even death. Eyes are relatively more sensitive to the formaldehyde. The concentration of this substance above $0.03 \mathrm{ppm}$ to $0.5 \mathrm{ppm}$ may cause burning sensation, itching, tearing and redness. In the case of formaldehyde levels exceed $100 \mathrm{ppm}$ or someone's eyes get in direct contact with it, the result is severe optical injuries. Loss of vision is the worst effect.

Direct contact with formaldehyde liquid can cause irritation, like rash and hives. Excessive exposure to formaldehyde is also reported to cause allergic contact dermatitis. Fabrics are widely treated with formaldehyde contained products, which increase the probability of skin irritation for some individuals who are prone to formaldehyde-induced allergy. A small number of studies have looked at the health effects of formaldehyde in children. It is very likely that breathing formaldehyde will result in nose and eye irritation (burning feeling, itchy, tearing, and sore throat). It is known if the irritation would occur at lower concentrations in children than in adults (ATSDR, 2008). Some studies of humans have suggested that formaldehyde exposure is associated with certain types of cancer at that time. The International Agency for Research on Cancer (IARC) identifies formaldehyde as a human carcinogen. The National Toxicology Program, an interagency program of the Department of Health and Human Services, named formaldehyde as a known human carcinogen (IARC, 2011)

Coagulation necrosis is caused by Ethephon. Hydrogen ions desiccate epithelial cells, causing edema, erythema, tissue sloughing, and necrosis, with the formation of ulcers and eschars. Irritation and partial thickness burns may be caused due to minor exposure. Due to high concentration exposure can lead to full thickness burns. Cellulitis, contractures, sepsis, osteomyelitis, and systemic toxicity are the main complications. It may develop deep burns and necrosis of the gastrointestinal mucosa. Complications sometimes include perforation (esophageal, gastric, rarely duodenal), fistula formation (tracheoesophageal, aorta oesophageal) and gastrointestinal bleeding. Upper airway edema is common and often life-threatening. Hypotension, tachycardia, tachypnea and, rarely, fever may develop. Other rare complications include metabolic acidosis, hemolysis, renal failure, disseminated intravascular coagulation, elevated liver enzymes, and cardiovascular collapse. Stricture formation (primarily gastric outlet and esophageal, less often oral) is likely to develop long term. Esophageal carcinoma is another long term complication. Severe toxicity is generally limited to deliberate ingestions in adults in the US because acidic products available in the home are generally of low concentration.

Calcium carbide has alkaline properties in nature and the mucosal tissue is irritated by the abdominal region. After eating carbide contain ripened mangoes, stomach 
upset has been addressed (Siddiqui and Dhua, 2010). Calcium carbide is the reason of neurological disorders as it has cancer responsible properties and causing. It can result in tingling sensation and peripheral neuropathy. Calcium Carbide releases acetylene which almost works like ethylene in terms of speeding up the ripening process. Direct consumption of acetylene has been found to be detrimental as it reduces oxygen supply to the brain and can further because of prolonged hypoxia. Calcium carbide may cause severe eye irritation with possible burns. Eye contact may result in permanent eye damage or blindness. It may cause severe burns, stinging pain, inflammation of eyelids and conjunctivitis, inflammation of eyelids, watering of eyes, opacity and scarring. Severe rash, burning feeling, skin irritation, and redness with possible burns may be caused by calcium carbide. Its contact with skin is responsible for possible burns and irritation if the skin is moist or wet. When in contact with moist skin, caustic lime is formed, which causes scarring and ulceration. Repeated/prolonged skin contact may cause dryness or rashes. Carbide is known to be carcinogenic (cancer inducing) substance and its consumption for long periods of time predispose one to a high risk of developing cancer and some other abnormalities in the stomach. The use of this chemical for the purposes of ripening fruits is illegal in most countries. It affects the neurological system, resulting in a headache, dizziness, mood disturbances, sleepiness, mental confusion, and seizures on a short-term basis, while in the long-term it can cause memory loss. Peptic ulcer may occur due to chronic exposure to the chemical. $\mathrm{CaC}_{2}$ may affect the neurological system by inducing prolonged hypoxia as it imitates acetylene gas. Some research findings similar to carbide poisoning have indicated dizziness, headache, mood disturbances, mental confusion, sleepiness, cerebral edema, memory loss, and seizures. Though eating the fruit will not bring about such an allergic reaction, the method of ripening it could cause such problems.

\section{Answerable organizations and rules for applying toxic chemicals in Bangladesh}

In respect of health related concerns, several acts and laws have been issued and implemented in developing and developed countries due to control the application of artificial fruit ripening toxic chemicals. Bangladeshi organizations and agencies are responsible ensuring the proper practice of examining, inspecting, harvesting, controlling, ripening and marketing of fruits like Bangladesh Ministry of Agriculture, Mobile court, BSTI (Bangladesh Standard and Testing Institute) Customs,
Ministry of Science, Ministry of Health. Bangladesh pure food (Amendment) Act, 2005 prohibits the use of any poisonous chemicals like calcium carbide, formalin, ethylene in any food that may cause harm to human body. These agencies implement the following laws and act in order to maintain the quality of the homegrown and imported fruits: Pesticide law 2007, Pure food rules and act 1967 and 2005, Quarantine rules 1968, Mobil court act 2009, and Penal code 1860 (FAO, 2010). Some directives have recently been issued by the Bangladesh high court for stopping the excess use of these toxic chemicals and some administrative drives are also being taken. Chemically applied fruits are being sold in open markets though it has legal prohibition. Nowadays there is a great importance on food safety by the Constitution of Bangladesh. According to the Bangladesh Constitution, article 15 of states 'it is a fundamental responsibility of the state to secure provision of the basic necessities of life including food'. According to article 18 of the Constitution states, 'State shall raise the level of nutrition and improve public health as its primary duties' (Government of Bangladesh, 1972). If anybody prohibits the above laws and acts by applying any toxic chemicals to ripen fruits artificially, he will penalize for mixing, selling and/or applying artificially ripened fruits. In developing countries like Bangladesh, fruit ripening by artificially toxic chemicals is a complex issue. Farmers, fruit-sellers, scientists, policymakers, government agencies and consumers need attention to combat this matter. It should be better to determine several aspects of artificial fruit ripening, standard practices investigation with carrying out appropriate scientific studies to make better the condition (Mursalat et al., 2013). A laboratory named 'The National Food Safety Laboratory' has been established in October 2012 at the Institute of Public Health, Dhaka, Bangladesh due to subdue present condition. The European Union and Netherlands financed the laboratory and has been built on FAO's technical assistance. There is increasing threat in the life and health of the Bangladeshi people for using formalin, calcium carbide, and other chemicals in the fruit (Siddiqui and Dhua, 2010).

\section{Conclusion}

According to Bangladesh pure food (Amendment) Act, 2005 and Formalin Control Act, 2015 control application of toxic chemical as formalin, calcium carbide, pesticides in pineapple that may cause harm to human body. Some unscrupulous traders' trade chemically treated fruits in markets all over Bangladesh despite legal prohibition. The government, law enforcing 
agencies and health authorities of the country should take more steps and pay attention to combat illegal application of hazardous toxic chemicals. Consumers should be aware of buying ripened pineapples. Running water should be used for a few minutes to wash pineapple. Use of natural pineapple ripening techniques should be recommended and fixed marketable time should be maintained for pineapple. At last, awareness should be generated to people by arranging campaign against the application of toxic chemicals in pineapple is mandatory. Diet protection from these toxic chemicals must be addressed one of the necessary public health functions of any country.

\section{Acknowledgments}

The authors thank Professor Dr. Mohammad Asadul Haque, Department of Soil Science, Patuakhali Science and Technology University, Patuakhali-8602, Bangladesh for his valuable suggestions and cordial cooperation.

\section{References}

Agency for Toxic Substances and Disease Registry (ATSDR). (1990). Toxicological profile for ethylene oxide. Atlanta, GA: U.S. Department of Health and Human Services, Public Health Service.

Agency for Toxic Substances and Disease Registry (ATSDR). (2008). Toxicological profile for Formaldehyde. (Draft for Public Comment). Atlanta, GA: U.S. Department of Health and Human Services, Public Health Service.

Anwar, R., Malik, A.U., Amin, M., Jabbar, A. and Saleem, B. A. (2008). Packaging material and ripening methods affect mango fruit quality. International Journal of Agricultural Biology, 10, 35 -41 .

Bartholomew, D.P., Paul, R. E. and Rorbach, K.G. (2003). The pineapple 'Botany, Production and Uses', University of Hawaii Manoa Honolulu, USA. Retrieved from: http://bookshop.cabi.org/Uploads/ Books/PDF/978085995038/

Baruwa, O.I. (2013). Profitability and constraints of pineapple production in Osun State, Nigeria. 2013. Journal of Horticultural Research, 21(2), 59-64. https://doi.org/10.2478/johr- 2013-0022.

Brady, C.J. (1987). Fruit Ripening. Annual Review of Plant Physiology and Plant Molecular Biology, 38, 155-178.https://doi.org/10.1146/ annurev.pp.38.060187.001103
Butterworth, B.E. and Chapman, J.R. (2007). Exposure of hematopoietic stem cells to ethylene oxide during processing represents a potential carcinogenic risk for transplant recipients. Regulatory Toxicology and Pharmacology, 49(1), 149-153. https:// doi.org/10.1016/j.yrtph.2007.07.004

Cua, A.U. and Lizada, M.C. (1990). Ethylene production in the 'Carabao' mango (Mangifera indica L.) fruit during maturation and ripening. Acta Horticulture, 269, 169-79. https://doi.org/10.17660/ ActaHortic.1990.269.22

FAO. (2010). Review of Food Safety and Quality Related Policies in Bangladesh, p. 1-28. Food and Agriculture Organization of the United Nations: Dhaka, Bangladesh.

Government of Bangladesh (GoB). (1972). Government of Bangladesh. The Constitution of the People's Republic of Bangladesh. Part II: Fundamental Principles of State Policy.

Hakim, M.A. Hakim, M.A., Obidul Huq, A.K., Alam, M.A., Khatib, A., Saha, B.K., Haque, K.M.F. and Zaidul, I.S.M. (2012). Role of health hazardous ethephon in nutritive values of selected pineapple, banana and tomato. Journal Food Agriculture and Environment, 10(2), 247-251.

Hoque, M.A. (2012). Action Against Unscrupulous Fruit Ripeners, in The Financial Express. Retrieved November 25, 2012: www.thefinancialexpressbd.com

International Agency for Research on Cancer (June 2004). IARC Monographs on the Evaluation of Carcinogenic Risks to Humans Volume 88 (2006): Formaldehyde, 2-Butoxyethanol and 1-tertButoxypropan-2-ol. Retrieved June 10, 2011, from: http://monographs.iarc.fr/ENG/Monographs/vol88/ index.php.

Islam, M.S., Ahmed, M.K., Al-Mamun, M.H. and Raknuzzaman, M. (2015). The concentration, source and potential human health risk of heavy metals in the commonly consumed foods in Bangladesh. Ecotoxicology and Environmental Safety, 122, 462469. https://doi.org/10.1016/j.ecoenv.2015.09.022

Jayan, T.V. (2011). Beware of These Fruits. Retrieved June 2, 2012 from The Telegraph: www.telegraphindia.com

Kendrick, M. (2009). The Origin of Fruit Ripening, in Scientific AmericanTM. Retrieved June 2, 2012 from Nature America website: www.scientificamerican.com

Koning, R.E. (1994). Fruit Ripening. Retrieved June 2, 
2012 from Plant Physiology Information Website: http://plantphys.info/plants_human/

fruitgrowripe.shtml.

Mariappan, P. (2004). How do raw mangoes and bananas become ripe when treated with chemicals (Answer-2)? India: The Hindu-Online edition of India's National Newspaper.

Mursalat, M., Rony, A.H., Rahman, A.H.M.S., Islam, M.N. and Khan, M.S. (2013). A critical analysis of artificial fruit ripening: Scientific, Legislative and Socio-Economic Aspects. CHE THOUGHTSChemical Engineering and Science Magazine, 4(1), 6-12.

Nagel, M.C. (1989). The Fruits of Ethylene. ChemMatters, 7(2), 11-13.

Rahim, M.A. (2012). Indiscriminate use of chemical in fruits and their health effects. Proceedings of First AFSSA Conference on Food Safety and Food Security, p. 17-25. Osaka, Japan: Osaka Prefecture University

Siddiqui, M.W. and Dhua, R.S. (2010). Eating Artificial Ripened Fruits is Harmful. Current Science, 99(12), 1664-1668.

Singal, S., Kumud, M. and Thakral, S. (2012). Application of apple as ripening agent for banana. Indian Journal of Natural Products and Resources, 3(1), 61-64.

Singh, Z. and Janes, J. (2001). Effect of postharvest application of ethephon on fruit ripening, quality and shelf life of mango under modified atmosphere packaging. Acta Horticulture, 553, 599-601. https:// doi.org/10.17660/ActaHortic.2001.553.141

United States Environmental Protection Agency (USEPA). (1988). Pesticide Fact Sheet Number 176: Ethephon. Washington, DC.: US EPA, Office of Pesticide Programs, Registration Division. 